\title{
Thoracic Pathologies on Scout Views and Bolus Tracking Slices for Computed Tomographic Cerebral Angiography
}

\section{Detektionsrate und -genauigkeit thorakaler Pathologien auf Topogrammen und Planungsschichten für die zerebrale CT-Angiografie}

Authors

Affiliations
M. Groth' ${ }^{1}$, J. Fiehler ${ }^{1}$, F. O. Henes ${ }^{2}$, J. H. Buhk ${ }^{1}$

Department of Diagnostic and Interventional Neuroradiology, University Medical Center Hamburg-Eppendorf, Hamburg, Germany

2 Department of Diagnostic and Interventional Radiology, University Medical Center Hamburg-Eppendorf, Hamburg, Germany

\author{
Key words \\ thorax \\ - cerebral angiography \\ - CT \\ - CT angiography
}

\begin{abstract}
received $\quad 5.1 .2015$
\end{abstract}
accepted 28.3.2015

\section{Bibliography}

Dol http://dx.doi.org/ 10.1055/s-0034-1399545

Published online: 27.5.2015 Fortschr Röntgenstr 2015; 187 : 691-696 @ Georg Thieme Verlag KG Stuttgart · New York . ISSN 1438-9029

\section{Correspondence}

\section{PD Dr. Michael Groth}

Department of Diagnostic and Interventional Radiology, Section for Pediatric Radiology, University Medical Center Hamburg-Eppendorf

Martinistr. 52

20246 Hamburg

Germany

Tel.: ++49/40/741052712

Fax: ++ 49/40/7 41054964

groth.michael@googlemail.com

\section{Zusammenfassung \\ $\nabla$}

Ziel: Evaluation der Inzidenz thorakaler Pathologien auf Topogrammen und Planungsschichten (TuP) der zerebralen CT-Angiografie (CTCA) sowie Prüfung der Detektionsgenauigkeit im Vergleich mit der thorakalen CT (TCT) als Goldstandard.

Material und Methoden: Es fand eine retrospektive Auswertung von 505 konsekutiven Patienten statt, bei denen eine CTCA durchgeführt wurde. Die zur Planung der jeweiligen CTCAs angefertigten TuP wurden auf das Vorhandensein thorakaler Pathologien untersucht. Darüber hinaus wurde durch eine Auswertung der Patientenakten geprüft, ob aufgrund der thorakalen Pathologien therapeutische Maßnahmen initiiert wurden. Bei 18 Patienten war unmittelbar in Anschluss an die CTCA eine TCT durchgeführt worden. Diese $18 \mathrm{~Pa}-$ tienten wurden zusätzlich von zwei geblindeten erfahrenen Radiologen bzgl. des Vorhandenseins thorakaler Pathologien auf TuP untersucht, um sowohl die Intra- und Interobserver-Reliabilität als auch die Genauigkeit in der Detektion dieser Pathologien zu evaluieren.

Ergebnisse: Auf 165/505 (33\%) TuP konnte jeweils mindestens eine thorakale Pathologie detektiert werden. Am häufigsten wurden folgende fünf Pathologien detektiert: Pleuraerguss (12\%), Infiltrat (8\%), Atelektase/Dystelektase (6\%), Perikarderguss $(2 \%)$ und Zwerchfellhochstand (1\%). $48 \%$ dieser thorakalen Pathologien erforderten therapeutische Konsequenzen. Im Vergleich mit dem Goldstandard TCT erreichten TuP eine Sensitivität von $53 \%$, eine Spezifität von 99\%, einen positiven prädiktiven Vorhersagewert von $89 \%$, einen negativen prädiktiven Vorhersagewert von $94 \%$ sowie eine Genauigkeit von $94 \%$. Die Intraobserver-Reliabilität war sehr gut, die InterobserverReliabilität moderat.

Schlussfolgerung: TuP, welche zur Planung von CTCA angerfertigt werden, sollten mit großer Sorgfalt interpretiert werden, da diese Pathologien das

\section{Abstract \\ $\nabla$}

Purpose: To evaluate the incidence of additional thoracic pathologic findings (TPF) detected on scout views and corresponding bolus tracking slices (SVBT) for computed tomographic cerebral angiography (CTCA) and to test the reliability and accuracy of these findings.

Materials and Methods: The study collective included 505 consecutive patients who underwent multidetector CTCA. Appendant SVBT of all patients were reviewed for any pathologic findings and patient medical reports were analyzed, if any medical treatment was initiated for the detected pathologic findings. In 18 patients thoracic CT scans were performed in the same session. These were additionally reviewed by two blinded observers to test for intra- and interobserver reliability as well as for accuracy of detecting thoracic pathologies on SVBT.

Results: TPF were detected in 165 (33\%) SVBT. The five most common pathologic findings were: pleural effusion, $12 \%$; pneumonia, $8 \%$; atelectasis/dystelecatsis, $6 \%$; pericardial effusion, $2 \%$ and elevated diaphragm, $1 \%$. For $48 \%$ of these findings medical treatment was initiated. SVBT showed a sensitivity of $53 \%$, a specificity of $99 \%$, a positive predictive value of $89 \%$, a negative predictive value of $94 \%$ and accuracy of $94 \%$ for the detection of TPF. The intraobserver reliability was very good and the interobserver reliability showed moderate agreement.

Conclusion: SVBT for CTCA should be reviewed with care by radiologists, since additional TPF can affect patient management. Nevertheless, despite a high specificity of SVBT for detecting TPF, an only moderate sensitivity has to be taken into account.

Key points:

- Thoracic pathologies are frequently found on scout views for cerebral CTA 
Patientenmanagement beeinflussen können. Dennoch sollte eine lediglich moderate Sensitivität im Vergleich zu einer hohen Spezifität bei der Detektionsrate berücksichtigt werden.

Kernaussagen:

- Thorakale Pathologien auf Planungstopogrammen für die zerebrale CTA sind sehr häufig

- Eine zusätzliche Auswertung von Planungsschichten erhöht die diagnostische Sensitivität

- Trotz hoher Spezifität bieten Topogramme und Planungsschichten nur eine moderate Sensitivität

- Die Begutachtung von Topogrammen und Planungsschichten kann therapeutische Konsequenzen haben
- Reviewing additional bolus trigger slices will improve diagnostic sensitivity

- Despite high specificity, scout views and trigger slices offer a moderate sensitivity

- Evaluation of scout views and trigger slices can result in medical treatment

Citation Format:

- Groth M, Fiehler J, Henes FO etal. Thoracic Pathologies on Scout Views and Bolus Tracking Slices for Computed Tomographic Cerebral Angiography. Fortschr Röntgenstr 2015; 187: 691-696

\section{Introduction}

$\nabla$

Multidetector computed tomographic cerebral angiography (CTCA) is used in many institutions for the initial evaluation of the cerebral circulation for acute ischemic stroke and subarachnoid hemorrhage as well as various pre- and post-operative settings $[1-4]$. For planning CTCA, scout views including the thorax, neck, and skull for defining the scan area as well as a bolus trigger slice are widely used [5].

Several studies showed the feasibility of CT scout views to reveal pathologies in different organ systems [6-8]. In some cases, clinically relevant pathologies may only be identified on scout views [9-11]. Nevertheless, to the best of our knowledge, no study has evaluated thoracic pathologies detected on scout views and corresponding bolus trigger slices (SVBT) for CTCA.

Therefore, the aim of this study was to evaluate the incidence of additional pathologic findings detected on SVBT for CTCA and - if possible - to test for the reliability and accuracy of these findings.

\section{Materials and Methods}

$\nabla$

\section{Study collective}

Institutional review board approval was obtained for this retrospective study. Moreover, the study was conducted according to the Declaration of Helsinki. We used our radiology information system (RIS) to identify 505 consecutive patients (274 female and 231 male; mean age, $65+/-15$ years) who underwent CTCA of the cerebral arteries between January 2010 and March 2012 at a 1400-bed university medical center.

\section{CTCA}

All CTCA studies were performed using a 256-slice multisection computed tomography system (Brilliance iCT, Philips, Best, the Netherlands). The patients assumed a supine position with their arms at their sides. Anterior and lateral scout views (tube voltage $120 \mathrm{kV}$, tube current $30 \mathrm{mAs}$ ) including the upper part of the thorax as well as the neck, and skull were acquired separately first. The CTCA scan range reached from the aortic arch to the vertex. Scan parameters were the following: rotation time $0.4 \mathrm{~s}$, collimation $64 \times 0.625$, tube voltage $120 \mathrm{kV}$, tube current 300 $\mathrm{mA} /$ slice. The scanning range was planned in a caudocranial direction. $60 \mathrm{ml}$ of nonionic contrast material with an iodine concentration of $400 \mathrm{mg} / \mathrm{ml}$ (Imeron 400, Bracco Altana Pharma, Milan, Italy) were injected at a rate of $4 \mathrm{ml} / \mathrm{s}$ through an 18-gauge peripheral intravenous catheter, which was placed in an antecubital vein, followed by a saline flush of $40 \mathrm{ml}$ at the same injection rate. Synchronization between the passage of contrast material and data acquisition was achieved with a bolus tracking technique, which is based on real-time monitoring of the main bolus during injection with the acquisition of a series of dynamic lowdose monitoring scans (slice thickness $10 \mathrm{~mm}$, tube voltage $120 \mathrm{kV}$, tube current $25 \mathrm{mAs}$ ) at the level of the vessel of interest [12]. In the present study CTCA scan was triggered automatically by means of a threshold, measured in a region of interest (ROI) set in the descending aorta. The threshold was set at $150 \mathrm{HU}$.

Image analysis and evaluation of additional medical data All SVBT were reviewed by one observer (MG, 6 years of experience in thoracic imaging). The observer was told to record pathologic findings for each CTCA patient. If the observer was uncertain regarding diagnosis, consensus readout was performed in collaboration with a second observer $(\mathrm{FOH}, 6$ years of experience in thoracic imaging). For further confirmation of the recorded pathologic findings, correlation with other imaging studies and/ or medical reports from the same hospital stay was performed. Moreover, medical reports were analyzed if any medical treatment was initiated for the detected pathologic findings.

To evaluate the intra- and interobserver reliability as well as the accuracy of detecting thoracic pathologies on SVBT, 18 consecutive imaging studies including CTCA and thoracic CT, both performed during the same imaging session, were reviewed by two observers (MG and FOH). Readout was repeated by one observer (MG) with a time interval of 12 weeks to test for intraobserver reliability. Furthermore, to investigate the accuracy for reviewing the anterior and lateral scout views alone, another readout including either anterior or lateral scout views was done by one observer (MG) more than 12 months after the initial readouts. The observers were told to report the presence or absence of 15 pathologic conditions for every examination resulting in $270 \mathrm{di}$ chotomous answer possibilities.

At our institution, in the daily clinical routine all thoracic CT examinations are interpreted by residents in a consensus readout with a faculty radiologist (experience level range from 7 to 29 years). These reports served as the gold standard for thoracic findings.

\section{Statistical analysis}

Statistical analysis was performed with a commercially available software tool (MedCalc for Windows, Mariakerke, Belgium and Excel, Microsoft Corporation, Redmond WA USA).

To evaluate the intra- and interobserver reliability, the Cohen's kappa coefficient was calculated to measure the degree of observer agreement regarding the presence or absence of different thoracic pathologies on SVBT for the above-mentioned 18 consecutive patients. A kappa value of up to 0.20 indicated positive but poor agreement, $0.21-0.40$ fair agreement, $0.41-0.6$ moderate 
agreement, $0.61-0.8$ good agreement, and greater than 0.8 very good agreement [13].

The sensitivity, specificity, positive predictive value (PPV), negative predictive value (NPV) with their 95\% confidence intervals (CI), and accuracy for the detection of pathologic findings on SVBT as well as anterior and lateral scout views alone compared with thoracic CT were calculated on the basis of true-positive, true-negative, false-positive, and false-negative rates [14].

\section{Results}

\section{Incidence of thoracic pathologies on SVBT}

A total of 180 pathologic conditions were recognized on SVBT. At least one pathologic finding was detected on 165 (33\%) SVBT. $113 / 180$ (63\%) pathologic conditions could be verified with other imaging studies and/or medical reports from the same hospital stay. Moreover, medical treatment was initiated for $87 / 180$ (48\%) of the pathologic findings. All thoracic pathologies detected on SVBT are listed in 0 Table 1. The five most common pathologic findings were: pleural effusion (12.1\%), pneumonia, (8.3\%), atelectasis/dystelecatsis (5.9\%), pericardial effusion (1.6\%), and elevated diaphragm (1.4\%). $\odot$ Fig. 1 - $\mathbf{3}$ show examples of detected thoracic pathologies.

\section{Intra- and interobserver reliability}

The intraobserver reliability showed very good agreement (Cohen's kappa coefficient: $0.86+/-0.06$ ) and moderate agreement was found for the interobserver reliability (Cohen's kappa coefficient: $0.49+/-0.06)$.

\section{Sensitivity, specificity, PPV, NPV, and accuracy}

The incidences of the 15 thoracic pathologies detected on 18 thoracic CT studies are listed in $\bullet$ Table 2. The sensitivity, specificity, PPV, and NPV for evaluation with SVBT as well as anterior or lateral scout views alone are listed in Tables 3-5. SVBT revealed an accuracy of $94 \%$ in detecting pathology. Accuracy was $89 \%$ for anterior or lateral scout views alone.

\section{Discussion}

$\nabla$

Thoracic pathologic findings (TPF) on SVBT could be detected in one third of CTCA. The five most often detected TPF included pleural effusion (12.1\%), pneumonia, (8.3\%), atelectasis/dystelectasis (5.9\%), pericardial effusion (1.6\%), and elevated diaphragm

Table 1 Pathologic findings detected on 505 scout views and corresponding bolus tracking slices (SVBT) and number of findings that could be confirmed (PP) by evaluating additional medical reports and/or imaging studies.

Tab. 1 Auf 505 Topogrammen und Planungsschichten (SVBT) detektierte Pathologien sowie Anzahl der Pathologien, welche durch eine Auswertung der Patientenakte und/oder anderer bildgebender Verfahren bestätigt werden konnten (PP).

\begin{tabular}{lcrlll}
\multicolumn{1}{l}{$\mathbf{n}(\%)$} & & & \\
\hline pathologic finding & \multicolumn{1}{l}{ SVBT } & \multicolumn{1}{l}{ PP } & MCP & \multicolumn{1}{l}{ IT } \\
\hline pleural effusion & $61(12.1)$ & $48(9.5)$ & $13(2.6)$ & $42(8.3)$ \\
\hline pneumonia & $42(8.3)$ & $28(5.5)$ & $14(2.8)$ & $28(5.5)$ \\
\hline dys-/atelectasis & $30(5.9)$ & $9(1.8)$ & $21(4.2)$ & $1(0.2)$ \\
\hline pericardial effusion & $8(1.6)$ & $3(0.6)$ & $5(1.0)$ & $2(0.4)$ \\
\hline elevated diaphragm & $7(1.4)$ & $4(0.8)$ & $3(0.6)$ & $0(0.0)$ \\
\hline incorrect intubation & $6(1.2)$ & $5(1.0)$ & $1(0.2)$ & $5(1.0)$ \\
\hline pneumothorax & $4(0.8)$ & $3(0.6)$ & $1(0.2)$ & $1(0.2)$ \\
\hline cardiomegaly & $4(0.8)$ & $3(0.6)$ & $1(0.2)$ & $2(0.4)$ \\
\hline thoracic adenopathy & $3(0.6)$ & $2(0.4)$ & $1(0.2)$ & $1(0.2)$ \\
\hline pulmonary nodule/mass & $3(0.6)$ & $0(0.0)$ & $3(0.6)$ & $1(0.2)$ \\
\hline pulmonary emphysema & $3(0.6)$ & $2(0.4)$ & $1(0.2)$ & $0(0.0)$ \\
\hline fibrosis & $2(0.4)$ & $0(0.0)$ & $2(0.4)$ & $0(0.0)$ \\
\hline aortic aneurysm & $2(0.4)$ & $1(0.2)$ & $0(0.0)$ & $0(0.0)$ \\
\hline incorrect central & $1(0.2)$ & $1(0.2)$ & $0(0.0)$ & $1(0.2)$ \\
venous access & & & & \\
\hline hiatal hernia & $1(0.2)$ & $0(0.0)$ & $1(0.2)$ & $0(0.0)$ \\
\hline subcutaneous & $1(0.2)$ & $1(0.2)$ & $0(0.0)$ & $0(0.0)$ \\
emphysema & & & & \\
\hline bone metastasis & $1(0.2)$ & $1(0.2)$ & $1(0.2)$ & $1(0.2)$ \\
\hline total & 180 & 113 & 97 & 87 \\
\hline
\end{tabular}

$\mathrm{MCP}=$ missing correlative proof; $\mathrm{IT}$ = number of pathologic findings for which medical treatment was initiated.

$\mathrm{MCP}=$ fehlende Bestätigung durch Patientenakte und / oder bildgebende Verfahren; IT = Anzahl der Pathologien, für welche eine therapeutische Konsequenz eingeleitet wurde.
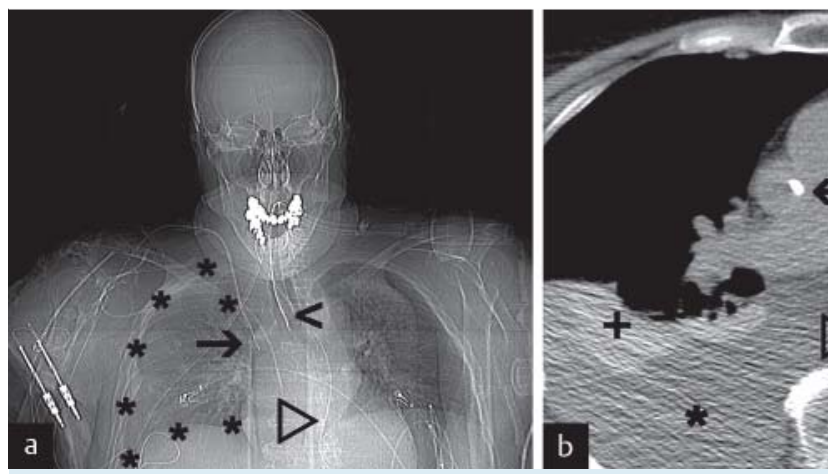

Fig. 1 62-year-old man who underwent CTCA for suspected ischemic stroke and thoracic CT for suspected pulmonary embolism. Scout view a and corresponding bolus trigger slice $\mathbf{b}$ as wall as thoracic $\mathrm{CT} \mathbf{c}$ revealed dystelectasis (cross in $\mathbf{b}, \mathbf{c}$ ) and pleural effusions (asterisk in $\mathbf{a}-\mathbf{c}$ ). Additionally, the locations of jugular and subclavian central venous devices (arrow in $\mathbf{a}-\mathbf{c}$ ), a tracheal tubus (arrowhead in a) and a gastric tube (triangle in $\mathbf{a}-\mathbf{c}$ ) can be identified.

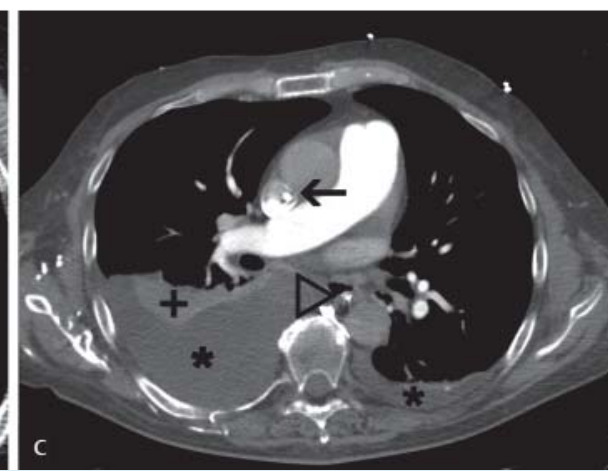

Abb. 1 62-jähriger Patient, welcher eine kranielle CT-Angiografie bei V.a. einen ischämischen Schlaganfall sowie ein anschließendes Thorax-CT bei $\checkmark$. a. eine Lungenembolie erhielt. Das Topogramm a, die Planungsschicht $\mathbf{b}$ und das Thorax-CT c zeigen dystelektatische Lungenareale (Kreuz in b, c) und Pleuraergüsse (Stern in $\mathbf{a}-\mathbf{c}$ ). Darüber hinaus lassen sich die Lokalisationen eines zentralvenösen Zuganges (Pfeil in $\mathbf{a}-\mathbf{c}$ ), eines Trachealtubus (Pfeilspitze in a) sowie einer Magensonde (Dreieck in a-c) abgrenzen. 

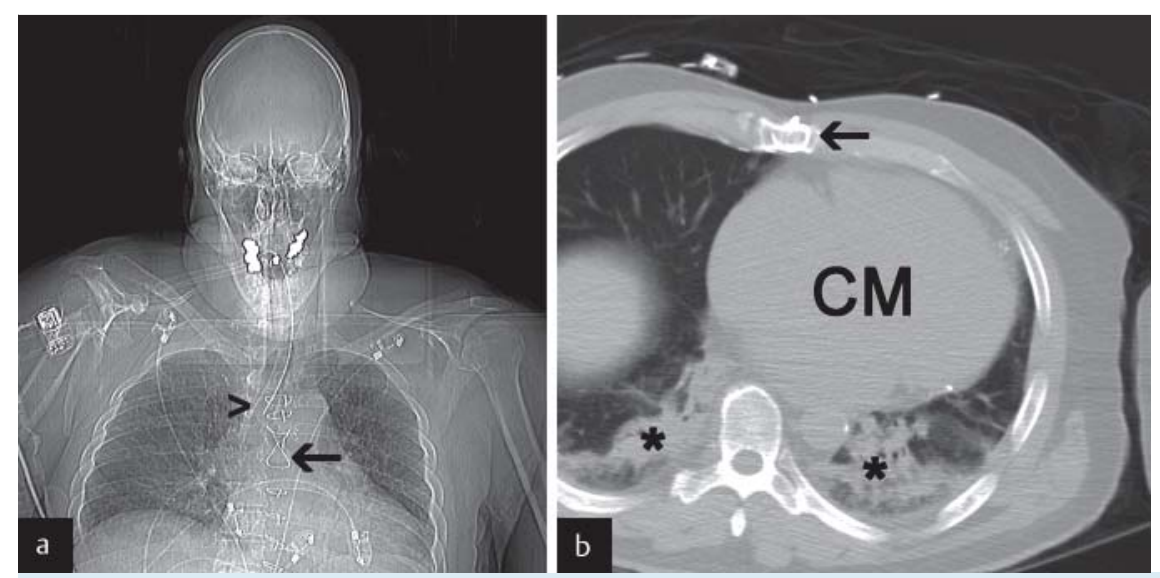

Fig. 2 Scout view a and corresponding bolus trigger slice $\mathbf{b}$ in a 60-year-old man who underwent CTCA for suspected basilar thrombosis. Unexpected thoracic findings include both-sided pneumonia that can be detected on the bolus trigger slice (asterisk in $\mathbf{b}$ ). Moreover, the location of a tracheal tubus above the tracheal carina can be identified on the scout view (arrowhead in a). Additionally, the patient presents with cardiomegaly (CM in b) caused by known insufficiency of the tricuspid and mitral valve and underwent sternotomy for coronary bypasses in the past (arrow in $\mathbf{a}, \mathbf{b}$ demonstrates sternal cerclages).

Abb. 2 Topogramm a und Planungsschicht b eines 60-jährigen Patienten, bei welchem eine kranielle CT-Angiografie bei V. a. eine Basilaristhrombose durchgeführt wurde. Als unerwarteter thorakaler Befund zeigt sich eine beidseitige Pneumonie, welche auf der Planungsschicht abgegrenzt werden kann (Stern in b). Darüber hinaus kann die Lage eines Trachealtubus auf dem Topogramm lokalisisert werden (Pfeilspitze in a). Zusätzlich zeigen sich eine Kardiomegalie (CM in b) bei bekannter Mitralklappeninsuffizienz sowie Sternalzerklagen bei Z. n. einer koronaren Bypass-Operation (Pfeil in a, b).
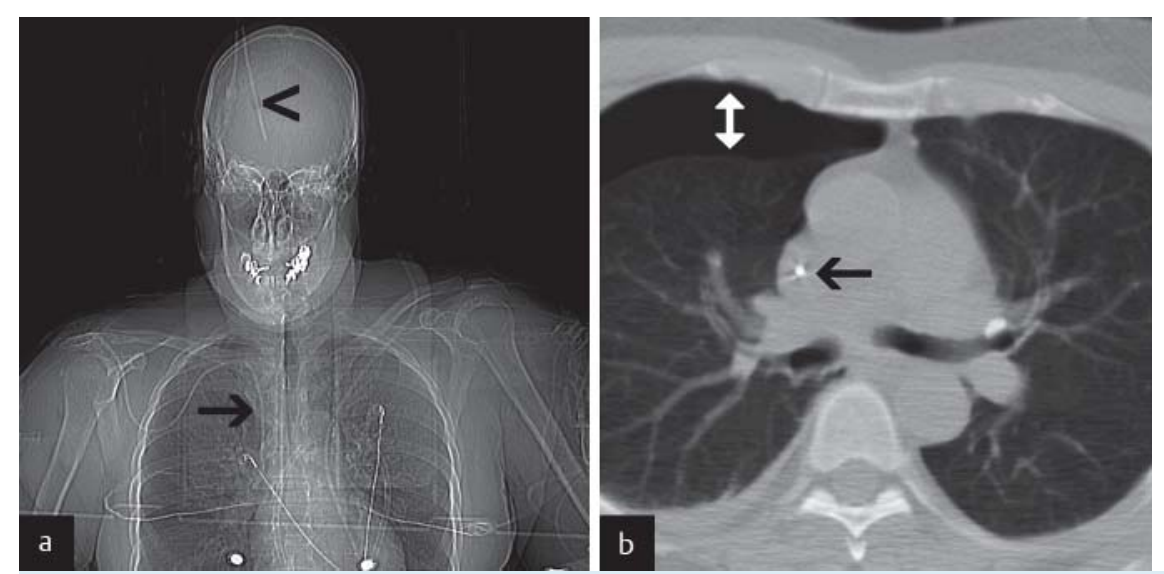

Fig. 3 Scout view $\mathbf{a}$ and corresponding bolus trigger slice $\mathbf{b}$ in a 62 -yearold woman suffering from acute subarachnoid hemorrhage who underwent CTCA for suspected intracranial aneurysm. latrogenic pneumothorax (double arrow in $\mathbf{b}$ ) caused by puncture of the subclavian vein for a central venous catheter (arrow in a, b) can be detected on bolus trigger slice. Additionally, a ventricular drain (arrowhead in a) was inserted before CTCA because of intraventricular hemorrhage.
Abb.3 Topogramm a und Planungsschicht b einer 62-jährige Patientin, bei welcher eine CTCA zur Aneurysmasuche bei Subarachnoidalblutung durchgeführt wurde. Es zeigt sich ein iatrogener Pneumothorax (Doppelpfeil in b) nach Punktion der Vena subclavia zur Anlage eines zentralvenösen Katheters (Pfeil in a, b). Darüber hinaus ist eine Ventrikeldrainage abzugrenzen (Pfeilspitze in a), welche vor der Durchführung der CTCA aufgrund einer Ventrikeleinblutung angelegt wurde.
(1.4\%). These findings are very similar compared with the top five TPF detected in another study that investigated additional TPF in patients undergoing thoracic CT for suspected pulmonary embolism [15].

Indication for CTCA includes various acute cerebrovascular diseases like suspected basilar thrombosis, occlusion of the middle cerebral artery or carotid pathology. Since patients with suspected acute cerebrovascular disease have sometimes already been put under general anesthesia when arriving in the emergency room [16], clinical examination might be hampered. Therefore, additional knowledge of TPF like pleural effusion, pneumonia or atelectasis on SVBT is very helpful for patient management.

A recent study showed that scout views for CT examinations of various anatomic regions like the head, neck, chest, pelvis, etc. revealed pathologic findings, which result in additional medical management in up to $23 \%$ of cases [17] (compared with $87 / 180$ (48\%) in our study). Only $2 \%$ of these pathologic findings were not included in the FOV of the CT examination. In contrast to this study, our study evaluated thoracic SVBT for CTCA. Therefore, all detected thoracic pathologic findings were not imaged in the CTCA FOV. Furthermore, a thoracic bolus trigger slice added additional information.

The sensitivity and specificity of detecting TPF on SVBT were $53 \%$ and $99 \%$, respectively. Furthermore, high accuracy of $94 \%$ was calculated. For detecting pathologies like pleural effusion and pneumonia on chest radiographs in the supine position, sensitivities/specificities/accuracies of 67\%/70\%/69\% [18] and 65\%/93\%/ $67 \%$ [19], respectively, were reported. Due to the small number of patients that underwent CTCA and thoracic CT during the same 
Table 2 Pathologic findings detected on 18 thoracic CT studies.

Tab. 2 Auf 18 Thorax-CTs detektierte Pathologien.

\begin{tabular}{|l|l|}
\hline pathologic finding & $\mathbf{n}$ \\
\hline pneumonia & 7 \\
\hline pleural effusion & 5 \\
\hline dys-/atelectasis & 4 \\
\hline thoracic adenopathy & 3 \\
\hline incorrect intubation & 2 \\
\hline rip fracture & 2 \\
\hline pericardial effusion & 1 \\
\hline edema & 1 \\
\hline pneumothorax & 1 \\
\hline pulmonary nodule/mass & 1 \\
\hline aortic dissection & 1 \\
\hline pulmonary embolism & 1 \\
\hline subcutaneous emphysema & 1 \\
\hline bone metastasis & 1 \\
\hline spinal fracture & 1 \\
\hline
\end{tabular}

Table 3 Sensitivity, specificity, positive predictive value (PPV), and negative predictive value (NPV) with their $95 \%$ confidence intervals (CI) for the detection of pathologic findings on scout views and corresponding bolus trigger slices.

Tab. 3 Sensitivität, Spezifität, positiver prädiktiver Vorhersagewert (PPV) und negativer prädiktiver Vorhersagewert (NPV) mit den jeweiligen $95 \%$ Konfidenz-Intervallen (CI) für die Detektion thorakaler Pathologien auf Topogrammen und Planungsschichten.

\begin{tabular}{|c|c|c|c|}
\hline & \multirow{2}{*}{$\begin{array}{l}\text { estimated } \\
\text { value }\end{array}$} & \multicolumn{2}{|l|}{$95 \% \mathrm{Cl}$} \\
\hline & & lower limit & upper limit \\
\hline sensitivity & $53 \%$ & $35 \%$ & $70 \%$ \\
\hline specificity & $99 \%$ & $97 \%$ & $100 \%$ \\
\hline PPV & $89 \%$ & $65 \%$ & $98 \%$ \\
\hline NPV & $94 \%$ & $90 \%$ & $96 \%$ \\
\hline
\end{tabular}

imaging session, decided subdivision of sensitivities, specificities, and accuracies for the different pathologies could not be analyzed in our study. However, one could consider at least similar accuracy of conventional chest radiography and SVBT in detecting overall pathologies. Especially pathologies like small pleural effusions are known to be frequently overlooked on chest radiographs [20]. An axial CT slice like a bolus trigger slice would be expected to be more accurate. However, evaluation of this assumption was not part of our study, but would be an interesting topic for future studies.

Since in some institutions scout views for CTCA are performed in one view only, sensitivity, specificity, PPV, NPV, and accuracy were evaluated for anterior and lateral views alone, as well. Especially for sensitivity, an obvious decrease could be observed for the anterior (19\%) and lateral (6\%) scout views compared to $53 \%$ for SVBT.

Summing up, careful reading of SVBT might detect relevant thoracic pathologies that require urgent management like pneumothorax, incorrect intubation, pericardial effusion and many more, which is especially useful in intubated and clinically hard to examine patients. In our study collective medical treatment was initiated for as much as $48 \%$ of TPF detected on SVBT.

Moreover, due to very good intraobserver and moderate interobserver reliability, SVBT offers high precision in detecting TPF. A Cohen's kappa coefficient of 0.49 for interobserver reliability is
Table 4 Sensitivity, specificity, positive predictive value (PPV), and negative predictive value (NPV) with their $95 \%$ confidence intervals (CI) for the detection of pathologic findings on the anterior scout views alone.

Tab. 4 Sensitivität, Spezifität, positiver prädiktiver Vorhersagewert (PPV) und negativer prädiktiver Vorhersagewert (NPV) mit den jeweiligen $95 \%$ Konfidenz-Intervallen ( $\mathrm{Cl}$ ) für die Detektion thorakaler Pathologien auf anterioren Topogrammen.

\begin{tabular}{|c|c|c|c|}
\hline & \multirow{2}{*}{$\begin{array}{l}\text { estimated } \\
\text { value }\end{array}$} & \multicolumn{2}{|l|}{$95 \% \mathrm{Cl}$} \\
\hline & & lower limit & upper limit \\
\hline sensitivity & $19 \%$ & $7 \%$ & $36 \%$ \\
\hline specificity & $99 \%$ & $96 \%$ & $100 \%$ \\
\hline PPV & $67 \%$ & $30 \%$ & $92 \%$ \\
\hline NPV & $90 \%$ & $86 \%$ & $93 \%$ \\
\hline
\end{tabular}

Table 5 Sensitivity, specificity, positive predictive value (PPV), and negative predictive value (NPV) with their $95 \%$ confidence intervals (CI) for the detection of pathologic findings on the lateral scout views alone.

Tab. 5 Sensitivität, Spezifität, positiver prädiktiver Vorhersagewert (PPV) und negativer prädiktiver Vorhersagewert (NPV) mit den jeweiligen 95\%Konfidenz-Intervallen ( $\mathrm{Cl}$ ) für die Detektion thorakaler Pathologien auf lateralen Topogrammen.

\begin{tabular}{|c|c|c|c|}
\hline & \multirow{2}{*}{$\begin{array}{l}\text { estimated } \\
\text { value }\end{array}$} & \multicolumn{2}{|l|}{$95 \% \mathrm{Cl}$} \\
\hline & & lower limit & upper limit \\
\hline sensitivity & $6 \%$ & $1 \%$ & $21 \%$ \\
\hline specificity & $100 \%$ & $98 \%$ & $100 \%$ \\
\hline PPV & $67 \%$ & $1 \%$ & $94 \%$ \\
\hline NPV & $98 \%$ & $84 \%$ & $92 \%$ \\
\hline
\end{tabular}

in line with another study, which found similar coefficients of 0.37 for the detection of pulmonary infiltration and 0.46 for the presence or absence of pleural effusion on chest radiographs [21]. Incidences of thoracic pathologies have been recorded on the basis of SVBT only. Validation by thoracic CT in each case would have been desirable but was not possible due to the retrospective character of the study. Therefore, the number of patients reviewed for testing reliability and accuracy of pathologic findings on scout views and corresponding bolus trigger slices is small and these results can only represent a vague estimation.

\section{Conclusion}

Based on the results of this study, we recommend that SVBT for CTCA should always be carefully inspected, since additional TPF can affect clinical patient management. Nevertheless, despite a high specificity of SVBT for detecting TPF, an only moderate sensitivity has to be taken into account.

\section{Clinical relevance}

- Thoracic pathologies are frequently found on scout views for cerebral CTA

- Reviewing additional bolus trigger slices will improve diagnostic sensitivity

- Despite high specificity, scout views and trigger slices offer a moderate sensitivity

- Evaluation of scout views and trigger slices can result in medical treatment 


\section{References}

1 Dimmick SJ, Faulder KC. Normal variants of the cerebral circulation at multidetector CT angiography. Radiographics 2009; 29: 1027-1043

2 Mair G, von Kummer R, Adami A et al. Observer reliability of CT angiography in the assessment of acute ischaemic stroke: data from the Third International Stroke Trial. Neuroradiology 2014

3 Schrader I, Wilk D, Jansen $O$ et al. Whole-brain perfusion CT using a toggling table technique to predict final infarct volume in acute ischemic stroke. Rofo 2013; 184: 975-982

4 Gierhake D, Weber JE, Villringer K et al. Mobile CT: technical aspects of prehospital stroke imaging before intravenous thrombolysis. Rofo 2013; 185: 55-59

5 Ernst M, Romero JM, BuhkJH et al. Sensitivity of visual and quantitative detection of middle cerebral artery occlusion on non-contrast-enhanced computed tomography. Neuroradiology 2014; 56: 1063-1068

6 Samelson EJ, Christiansen BA, Demissie S et al. Reliability of vertebral fracture assessment using multidetector CT lateral scout views: the Framingham Osteoporosis Study. Osteoporos Int 2011; 22: 11231131

7 Rosenblat JM, Rozenblit AM, Wolf EL et al. Findings of cecal volvulus at CT. Radiology 2010; 256: 169-175

8 Assi Z, Platt JF, Francis IR et al. Sensitivity of CT scout radiography and abdominal radiography for revealing ureteral calculi on helical CT: implications for radiologic follow-up. Am J Roentgenol Am J Roentgenol 2000; 175: $333-337$

9 Emamian SA, Dubovsky EC, Vezina LG et al. CT scout films: don't forget to look! Pediatr Radiol 2003; 33: 535-539

10 Sener RN, Ripeckyj GT, Otto PM et al. Recognition of abnormalities on computed scout images in CT examinations of the head and spine. Neuroradiology 1993; 35: 229-231

11 Hunter TB, Taljanovic MS. Medical devices of the abdomen and pelvis. Radiographics 2005; 25: 503-523
12 Cademartiri F, Nieman $K$, van der Lugt A et al. Intravenous contrast material administration at 16-detector row helical CT coronary angiography: test bolus versus bolus-tracking technique. Radiology 2004; 233: $817-823$

13 Brennan P, Silman A. Statistical methods for assessing observer variability in clinical measures. BMJ 1992; 304: 1491 - 1494

14 Branson HM, Doria AS, Moineddin R et al. The brain in children: is contrast enhancement really needed after obtaining normal unenhanced CT results? Radiology 2007; 244: 838 - 844

15 Groth M, Henes FO, Mayer $U$ et al. Age-related incidence of pulmonary embolism and additional pathologic findings detected by computed tomography pulmonary angiography. Eur J Radiol 2012; 81: 1913 1916

$16 \mathrm{Ng} K \mathrm{~K}$, Venketasubramanian N, Yeo LL et al. Usefulness of CT angiography for therapeutic decision making in thrombolyzing intubated patients with suspected basilar artery thrombosis. J Neuroimaging 2012; 22: $351-354$

17 Johnson PT, Scott WW, Gayler BW et al. The CT scout view: does it need to be routinely reviewed as part of the CT interpretation? Am J Roentgenol Am J Roentgenol 2014; 202: 1256 - 1263

18 Ruskin JA, Gurney JW, Thorsen MK et al. Detection of pleural effusions on supine chest radiographs. Am J Roentgenol Am J Roentgenol 1987; 148: $681-683$

19 Esayag Y, Nikitin I, Bar-Ziv J et al. Diagnostic value of chest radiographs in bedridden patients suspected of having pneumonia. Am J Med 2010; 123: 88 e81 - e85

20 Kitazono MT, Lau CT, Parada AN et al. Differentiation of pleural effusions from parenchymal opacities: accuracy of bedside chest radiography. Am J Roentgenol Am J Roentgenol 2010; 194: 407-412

21 Albaum MN, Hill LC, Murphy M et al. Interobserver reliability of the chest radiograph in community-acquired pneumonia. PORT Investigators. Chest 1996; 110: $343-350$ 